Original Research Article

\title{
Objective assessment of handwriting in outpatient prescriptions of a tertiary care hospital
}

\author{
Prafull Mohan ${ }^{1}$, Pooja Gupta ${ }^{2 *}$
}

${ }^{1}$ Department of Pharmacology, Armed Forces Medical College, Pune, Maharashtra, India ${ }^{2}$ Department of Pharmacology, All India Institute of Medical Sciences, New Delhi, India

Received: 28 May 2019

Revised: 07 June 2019

Accepted: 12 June 2019

\section{*Correspondence to:}

Dr. Pooja Gupta,

Email: drgupta.pooja@ gmail.com

Copyright: (C) the author(s), publisher and licensee Medip Academy. This is an openaccess article distributed under the terms of the Creative Commons Attribution NonCommercial License, which permits unrestricted noncommercial use, distribution, and reproduction in any medium, provided the original work is properly cited.

\begin{abstract}
Background: Poor physician handwriting may lead to wrong comprehension and dispensing errors. This study was planned to objectively assess the quality of handwriting of doctors and their readability by physician, pharmacist and patient and to explore the impact of experience and familiarity of pharmacist on prescription readability.

Methods: A 100 prescriptions were selected and were given to a pharmacist, a doctor and an educated lay person. They rated the readability of prescriptions on a scale of 1-10 and an average readability score was calculated. Prescriptions with average score 4 or less were subjected to analysis by a pharmacist working at the hospital dispensary (P1) and another pharmacist not working at hospital pharmacy (P2).

Results: Average score of pharmacist, physician and lay person was 6.14, 5.2 and 3.14 respectively. A total of 28 prescriptions, containing 93 medicines, had an average readability score of 4 or less. P1 was not able to comprehend one medicine while P2 could not comprehend 19 medicines out of these 93. The performance of both pharmacists was compared by diagnostic tests (EPI 6.04D). The sensitivity of P2 was $80 \%$ (95\% CI 70.6-87.7), specificity and positive predictive value were 100, and negative predictive value was $5.3(0.3-28.1)$.

Conclusions: Familiarity of the pharmacist with the prescribing physicians' handwriting is an important factor in comprehension of poorly legible prescriptions. This could limit the patients to pharmacists around the prescribers. Implementation of appropriate steps need to be assured to minimize the prescription errors.
\end{abstract}

Keywords: Dispensing errors, Medication errors, Objective assessment, Physician handwriting

\section{INTRODUCTION}

Prescribing medicines to patients is an integral part of medical care. It involves decision making about the choice of medicines, its communication to pharmacist in the form of prescriptions for dispensing and finally, the administration of medicines. The whole process requires seamless communication at various stages. However, a decremental knowledge gap exists at each step, with patient being almost totally unaware of the benefits and risks of medicines. Like any other process involving multiple individuals, this process too is prone to errors with the potential of jeopardizing patient care. Ensuring flawless delivery of correct medication to the patients is now drawing long deserved attention from health care professionals. It has become an important part of overall 
efforts for judiciously using medicines and minimizing their adverse effects. An error can occur at any stage of the prescription process viz:

\section{Choosing a medicine}

- There may be selection of irrational, inappropriate or ineffective (a medicine that is not effective for the indication in general or for a specific patient) medication,

- Under-prescribing (failure to prescribe a medicine that is indicated and appropriate, or use of too low a dose of an appropriate medicine)

- Over-prescribing (prescribing a medicine too much, too often or for too long).

\section{Prescription writing}

Omission/mistake in superscription, dosage form, strength of preparation, improper route and/or illegible handwriting contribute towards such errors.

\section{Formulation used}

Such errors may be contributed due to wrong strength, contaminants, wrong or misleading packaging of formulations involved.

\section{Dispensing of medication}

Dispensing wrong medicine or wrong formulation to the patient or dispensing medicines with wrong labeling can result in such errors.

\section{Administering/taking the medicine}

Despite justified selection of medicines, dose, correct dispensing, the patient may be administered or take medicine in wrong amount, by wrong route, in wrong frequency or for wrong duration.

\section{Monitoring therapy}

Failing to alter therapy when required or erroneous alteration account for such errors. ${ }^{1}$

An error occurring at any of these stages may result in failure of the therapy or may cause harm to the patient and is defined as medication error. In one study, inpatient medication errors occurred at the rate of $1.5-5.3$ per 100 orders. $^{2}$ In another study, $16 \%$ patients reported a medication error with two third being in OPD. ${ }^{3}$ These errors tend to have a negative impact on patients' health. ${ }^{4-}$ ${ }^{6}$ In one study, $11 \%$ adverse events were due to medication errors. ${ }^{7}$ Handwriting skills of physicians are generally perceived to be poor and handwritten prescriptions (and their illegibility) are a common satirical target. As per one study, compared to other healthcare professionals and administrators, physicians had the worst handwriting of all. ${ }^{8}$ In a 1986 study from the New England Journal of
Medicine, out of 50 outpatient progress notes, $16 \%$ of all words were illegible. ${ }^{9}$ A survey from Italy had revealed that 1 in 4 prescriptions was either not fully written or was illegible. ${ }^{10}$ In an Indian study, a significant number of prescriptions $(17.6 \%)$ were written in illegible handwriting and were not easily readable. ${ }^{11}$ In another study, handwriting samples of various healthcare executives, clinicians and managers working in healthcare setup were analysed in a time limited manner. In this study, doctors' handwriting was not found to be worse as compared to other executives. ${ }^{12}$ It is commonly acknowledged that some such poorly legible prescriptions are prone to wrong interpretation by the pharmacists and therefore may lead to medication errors while dispensing medicines. Indeed, there have been case reports where poorly legible handwriting led to significant patient harm. In one such report, an asthmatic patient was prescribed Amoxil, an anti-infective but was dispensed "daonil," an anti-diabetic drug as the pharmacist misinterpreted poor lower case handwriting on the prescription. This resulted in severe and dangerous hypoglycemia for the patient. ${ }^{13}$ Despite general acknowledgment and awareness regarding potential fallout of poor handwriting of doctors, there are few published studies that objectively grade the magnitude of the problem and estimate the adverse fallout of the same. In view of the above, this study was planned to objectively assess the quality of handwriting of doctors vis a vis their readability by various stakeholders viz physician, pharmacist and patient. This study further explores the impact of experience and familiarity of the pharmacist on his ability to comprehend handwritten prescriptions.

\section{METHODS}

This was an open label survey carried out in the Department of Pharmacology. A 100 prescriptions were randomly selected from the hospital dispensary located within the hospital premises. These prescriptions were given to a pharmacist not working in hospital dispensary; a doctor and an educated (graduate) lay person. All three were asked to rate the readability of study prescriptions on a scale of 1-10 with 1 indicating completely illegible prescription and 10 indicating fully legible one. The readability score was calculated after taking the average of three scores thus obtained. The prescriptions with readability score less than 4 were considered to be poorly legible and further subjected to analysis by a pharmacist working at hospital dispensary for at least 6 months (P1) and another pharmacist not working at the hospital pharmacy (P2). Both the pharmacists were asked to analyse the prescription and list out the medicines/ formulations they are able to easily comprehend/ understand against such prescriptions without taking the help of their colleagues and/or referring the patient back to prescribing doctor for clarifications. The feedback thus obtained was compared for difference in comprehension. The statistical analysis was done using GraphPad InStat and EpiInfo. The data is expressed as percentages. Kruskal-Wallis and McNemar tests were used for 
statistical significance. A p value $<0.05$ was considered as significant.

\section{RESULTS}

A total of 100 prescriptions were analysed for readability on a random scale of 1-10. Pharmacist found it easiest to comprehend the prescriptions (average readability score of 6.14) followed by physician (score 5.2) and educated lay person (score 3.14). The difference between the three was statistically significant $(\mathrm{p}<0.001$; Figure 1$)$.

A total of 28 prescriptions (28\%) were found to have an average readability score of $\leq 4$ and were segregated for further sub analysis. These prescriptions had a total of 93 medicines/ formulations prescribed amongst them. Out of them, P1 was not able to comprehend one medicine/ formulation and P2 was not able to comprehend 19 medicines/ formulations ( $p$ value $<0.0001$; Figure 2). Authors further assumed the performance of $\mathrm{P} 1$ to be the gold standard and compared the performance of P2 with that of P1. The sensitivity of P2 was $80 \%$ (95\% CI 70.687.7 ), specificity and positive predictive value were 100 , and negative predictive value was $5.3(0.3-28.1)$.

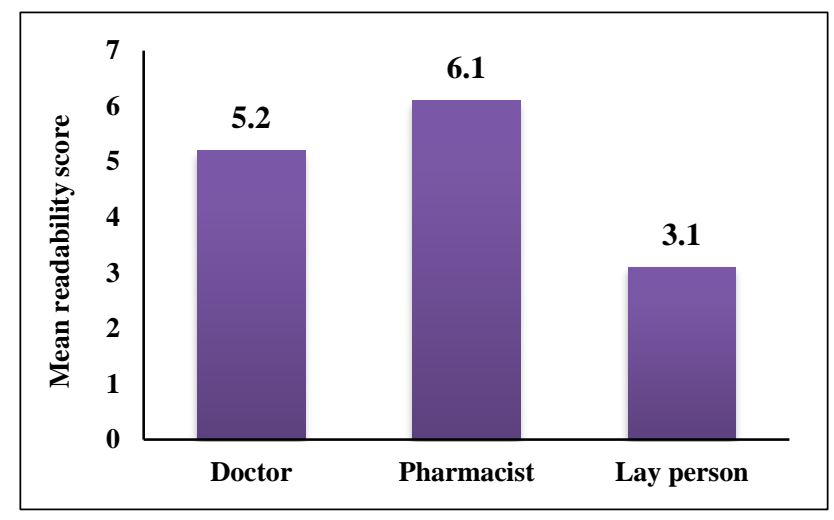

Figure 1: Average readability scores of three observers for 100 prescriptions ( $p$ value $<0.001$ ).

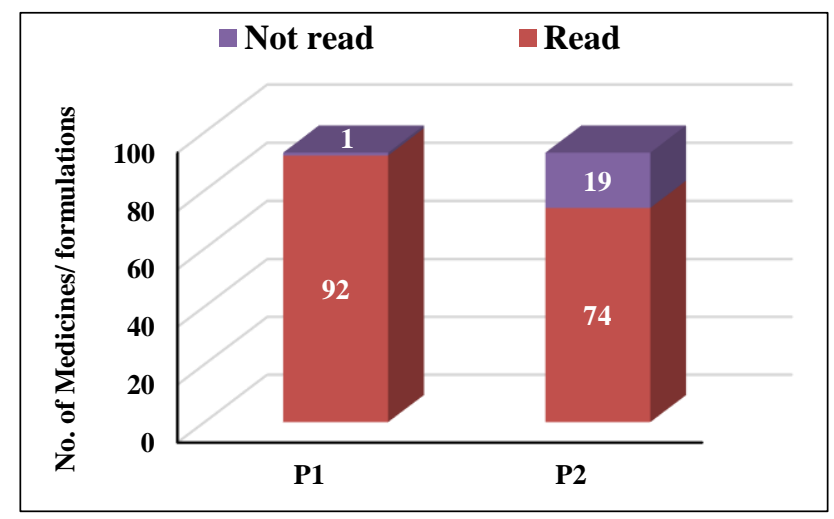

Figure 2: Number of prescribed medicines/ formulations not read (upper) and read (lower) by two observing pharmacists (P1-pharmacist working in study hospital; P2-pharmacist not working in the study hospital; $p$ value $<\mathbf{0 . 0 0 0 1 )}$.

\section{DISCUSSION}

This study attempted to undertake an objective assessment of handwriting of doctors by analysis of randomly selected OPD prescriptions. The study incorporated inputs from all stakeholders viz. doctor pharmacist, doctor and patient (represented by a graduate lay person) and then arrived at a composite score. Since the methodology adopted in this study has not been validated or used earlier, this study represents an initial attempt to grade the handwriting of doctors on an objective scale.

Out of 100 prescriptions, 28 prescriptions (28\%) were found to be poorly legible which is slightly higher as compared to those reported previously. ${ }^{10,11}$ The most ignorant and thus the weakest link in the process of 'prescribing-dispensing-consuming' is the patient and this is reiterated in this study as the educated lay person found it the most difficult to comprehend the prescriptions. We included educated (graduate) lay person who otherwise was well versed with English. It may be safely assumed that the comprehension of prescriptions would be even poorer in general population.

Prescriptions with poor score were segregated and they contained 93 medicines/formulations amongst them. These prescriptions were further analysed separately by two pharmacists-one working in study hospital (involved in routine dispensing) and the other working in Department of Pharmacology (involved in academics and research). The hospital pharmacist was able to comprehend 92 formulations while the other pharmacist was able to comprehend 74 formulations. Both the pharmacists had similar training, the only difference being the experience of working in the particular pharmacy. This difference in ability to easily read and understand prescriptions was statistically significant. It can be inferred that pharmacist 1 was able to perform better as he was familiar with the prescription pattern and the handwriting of the prescribing physicians. This difference was further analysed with the assumption that the performance of pharmacist 1 was the gold standard. Pharmacist 2 was able to read $20 \%$ less prescriptions as compared to what pharmacist 1 could. The specificity of pharmacist 2 was $100 \%$ as the prescription not understood by pharmacist 1 was not read by pharmacist 2 also. This study vindicates the intuitive conclusion that the experience and familiarity of the pharmacist with the handwriting of physicians plays a role and facilitates better comprehension of prescriptions by the pharmacist. It follows that the understanding and comprehension of a pharmacist is lowest in the beginning and he is more vulnerable to commit dispensing errors. With continued exposure, his/ her understanding shall improve and his performance can improve by up to $20 \%$. However, the actual impact of such experience on the number of medication errors remains to be studied.

The limitation of the study is small sample size. Larger studies involving larger number of pharmacists are required to accurately capture the effect of experience and 
familiarity on the performance and reliability of pharmacists.

\section{CONCLUSION}

In this study, about one fourth prescriptions had poor legibility. Experienced pharmacist working in hospital dispensary was able to comprehend even poorly legible prescriptions which could not be read by an equally qualified person who lacked practical experience of working in the hospital pharmacy. This study tries to outline the magnitude of problem of poorly legible prescriptions. However, due to small sample size, novel unvalidated methodology and simple analysis, the study results need to be substantiated.

\section{ACKNOWLEDGEMENTS}

Authors would like to thank $\mathrm{Mr}$ Sachin Kumar, $\mathrm{PhD}$ scholar and Mr. Nasib Usman, research trainee, for assisting with the work.

\section{Funding: No funding sources}

Conflict of interest: None declared

Ethical approval: Not required

\section{REFERENCES}

1. Aronson JK. Medication errors: what they are, how they happen, and how to avoid them. QJM. 2009; 102(8):513-21.

2. Dean B, Schachter M, Vincent C, Barber N. Prescribing errors in hospital inpatients: their incidence and clinical significance. Qual Saf Health Care. 2002;11(4):340-4.

3. Davis K, Schoenbaum SC, Collins KS, Tenney K, Hughes DL, Audet AMJ. Room for improvement: patients report on the quality of their health care, The Commonwealth Fund, April 2002. Available at: https://www.commonwealthfund.org/publications/fun d-reports/2002/apr/room-improvement-patients- report-quality-their-health-care. Accessed on 17 May 2019.

4. Lapointe NM, Jollis JG. Medication Errors in hospitalized cardiovascular patients. Arch Intern Med 2003;163(12):1461-6.

5. Jenkison ML. Prescribing errors. Lancet 2002;360(9328):256.

6. Hennessy S, Bilkar WB, Zhou L, Weber AL, Bresinger $\mathrm{C}$, Wang $\mathrm{Y}$, et al. Retrospective drug utilization review, medication errors, and clinical outcomes. JAMA. 2003;290(11):1494-9.

7. Gandhi TK, Weingart SN, Borus J, Seger AC, Peterson J, Burdick E, et al. Adverse drug events in ambulatory care. New Engl J Med. 2003;348(16):1556-64.

8. Lyons R, Payne C, McCabe M, Fielder C. Legibility of doctors' handwriting: quantitative comparative study. BMJ. 1998;317(7162):863-44.

9. White KB, Beary JF 3rd. Illegible handwritten medical records. N Engl J Med. 1986;314(6):390-1.

10. Calligaris L, Panzera A, Arnoldo L, Londero C, Quattrin R, Troncon MG, et al. Errors and omissions in hospital prescriptions: a survey of prescription writing in a hospital. BMC Clin Pharmacol. 2009;9(1):9.

11. Phalke VD, Phalke DB, Syed MM, Mishra A, Sikchi S, Kalakoti P. Prescription writing practices in a rural tertiary care hospital in western Maharashtra, India. Australas Med J. 2011;4(1):4-8.

12. Berwick DM, Winickoff DE. The truth about doctors' handwriting: a prospective study. BMJ 1996;313(7072):1657-8.

13. Brahams D. Uninsured pharmacists and illegible prescriptions. Lancet. 1989;1(8636):510.

Cite this article as: Mohan P, Gupta P. Objective assessment of handwriting in outpatient prescriptions of a tertiary care hospital. Int J Basic Clin Pharmacol 2019;8:1523-6. 